\title{
CrystEngComm
}

Check for updates

Cite this: CrystEngComm, 2021, 23, 1785

Received 18th November 2020,

Accepted 8th January 2021

DOI: $10.1039 / \mathrm{d} 0 \mathrm{ce} 01672 \mathrm{a}$

rsc.li/crystengcomm

\section{Developing design tools for introducing and tuning structural order in ionic liquids $\uparrow$}

\author{
Olivier Renier, (iD a Guillaume Bousrez, (DD ${ }^{a}$ Mei Yang, ${ }^{\text {b }}$ Milena Hölter, ${ }^{\text {b }}$ Bert Mallick, ${ }^{\text {b }}$ \\ Volodymyr Smetana (iD ${ }^{a}$ and Anja-Verena Mudring (iD*ab
}

\begin{abstract}
Ionic liquids (ILs) are receiving growing interest as highly tunable, multifunctional materials. Remarkably for liquids, they tend to display a high level of structural order. This structural order may even lead to the formation of mesophases such as liquid crystals (LCs). Imidazolium compounds are by far the most popular ILs, because they offer a widely versatile platform for property tuning. To investigate what is driving structural order in imidazolium-based ILs a series of asymmetrical 1-dodecyl-2-methyl-3-alkylimidazolium bromides, $\left[\mathrm{C}_{12} \mathrm{C}_{1} \mathrm{C}_{n}\right.$ im] $[\mathrm{Br}]$ with $n=0-12$ have been synthesized, fully characterized and their structures and properties compared with the analogous 1-dodecyl-3-alkylimidazolium as well as the 1,2,3-triazolium bromides. The aim is to examine the influence of the replacement of the most acidic $2-\mathrm{H}$ proton on the imidazolium head group by methylation on the properties and structure of ILs. For all compounds, except for compounds with butyl- and hexyl-chains as well as the protonated species, mesophase formation can be observed. Obviously, the simple presence of long alkyl chains such as dodecyl (a design concept frequently put forward in the literature) is not sufficient to support mesophase formation alone. Rather, for the formation of a liquid crystalline phase, a balance between attractive van der Waals forces, hydrogen bonds, and electrostatic interactions is required. Data from temperature-dependent small-angle X-ray scattering (SAXS) and polarizing optical microscopy (POM) suggest three different cation conformations for the studied $\left[\mathrm{C}_{12} \mathrm{C}_{1} \mathrm{C}_{n} \mathrm{im}\right][\mathrm{Br}]$ : cations with $0 \leq n \leq 4$ exhibit a near-linear conformation; for $5 \leq n \leq 10$ a $\mathrm{V}$-shape is adopted, and for $n=11$ or 12 a $\mathrm{U}$-shape is found. We demonstrated that the structural possibility for an interdigitation of the long chains is an influential factor for the formation of a mesophase.
\end{abstract}

\section{Introduction}

Imidazolium-based ionic liquids (ILs) have become an extremely popular class of compounds over the past decade due to their unique properties and large number of applications. ${ }^{1-8}$ ILs are generally defined as salts exhibiting a melting point below $100{ }^{\circ} \mathrm{C} .{ }^{9,10}$ Hydrogen-bonding interactions in these ILs mainly involving the hydrogen atom located on the $\mathrm{C} 2$ position of the imidazolium head group, have been found to play an important role in the order of the IL. ${ }^{11-15}$ They lead to the formation of supramolecular structures,

\footnotetext{
${ }^{a}$ Physical Materials Chemistry, Department of Materials and Environmental Chemistry, Stockholm University, Svante Arrhenius väg 16c, 10691 Stockholm, Sweden. E-mail: anja-verena.mudring@mmk.su.se

${ }^{b}$ Anorganische Chemie III - Materials Engineering and Characterization, Fakultät für Chemie and Biochemie, Ruhr-Universität Bochum, 44780, Bochum, Germany $\dagger$ Electronic supplementary information (ESI) available: Experimental details, instrumentation, SCXRD table, NMR spectra, IR spectra, TGA spectra, DSC traces, SAXS and POM. CCDC 1912603-1912605. For ESI and crystallographic data in CIF or other electronic format see DOI: 10.1039/d0ce01672a
}

which can be beneficially used in the designed synthesis of new materials. For example, they can be used for templating open-framework materials, ${ }^{16}$ to allow the morphological control of nanoparticles ${ }^{17}$ and even for phase control of polymorphic materials. ${ }^{18}$ These effects rely both on the interaction of the IL ions with each other, leading to the formation of a highly structured solvent where clear segregation of domains occurs, ${ }^{19,20}$ but also on the interaction of the IL ions with the solutes and nuclei of materials formed in them during synthesis. It is believed that hydrogen-bonding plays an important role in both interactions. ${ }^{21,22}$ Indeed, it has been observed that altering or blocking possible hydrogen-bonding sites significantly affects the physicochemical properties of the corresponding ILs by inducing drastic changes in the interactions and structures. ${ }^{14,23}$ In imidazolium ILs, the proton at the $\mathrm{C} 2$ position is known to interact strongly with the IL anion through hydrogen bonds. ${ }^{24}$ The introduction of a methyl group on the $\mathrm{C} 2$ position is therefore thought to cause significant property changes of these ILs, ${ }^{23,25}$ such as an increase in the melting points, ${ }^{26-28}$ viscosities ${ }^{29}$ and thermal- or chemical stabilities, ${ }^{26,29,30}$ along with a decrease in densities ${ }^{31}$ 
and polarities. ${ }^{32}$ Even the chemical reactivity can be affected after C2 methylation. ${ }^{33}$

Mesophase formation was observed for 1-alkyl-3-methylimidazolium bromides when the substituted alkyl chains contained twelve carbon atoms or more. ${ }^{34} \mathrm{~A}$ mesophase, like a liquid crystalline phase, is an intermediate between state the perfectly ordered crystalline and the disordered liquid state. ${ }^{35}$ ILs which are able to form a liquid crystalline phase are also addressed as ionic liquid crystals (ILCs). ILCs combine the selforganization features of liquid crystals and the solvent properties of ILs. ${ }^{36}$ The importance of ILCs has been realized in diverse applications such as ion-conductive materials, organized media or self-assembled nanostructured materials. ${ }^{36-43}$ Thus, it is of strong interest to understand how structural order can be introduced into ILs and learn which kind of secondary bonding forces evoke it. It was proposed that van-der-Waals interactions become so strong in 1-alkyl-3-methylimidazolium salts when the alkyl chain reaches twelve carbon atoms that LC formation induced. $^{32}$ However, aside from van der Waals interactions, hydrogen-bonds have been found to be involved in the formation of liquid crystalline phases. ${ }^{7,44}$ There is experimental evidence that methylation of the $\mathrm{C} 2$ position of an imidazolium cation can decrease or even eliminate the liquid crystallinity. ${ }^{45}$ However, for 1-hexadecyl-2,3-dimethylimidazolium bromide, a mesophase formation has been reported. ${ }^{46}$ Thus, increasing the lengths of the alkyl-tails and enhancing van der Waals interactions between the IL cations can outbalance the effect of $\mathrm{C} 2$ methylation in imidazolium bromides. So far, no understanding between mesophase formation, i.e. liquid crystallinity, hydrogen-bond ability as well as the influence of van der Waals forces has been reached for ILs, ${ }^{47}$ and the effect of a change in the H-donor site on the imidazolium ring on the liquid crystalline behaviour is yet to be determined. For this reason, we have prepared a series of 1-dodecyl-2-methyl-3-alkylimidazolium bromides $\left(\left[\mathrm{C}_{12} \mathrm{C}_{1} \mathrm{C}_{n} \mathrm{im}\right][\mathrm{Br}], n=0-12\right)$ (Scheme 1). The thermal and structural properties are investigated via differential scanning calorimetry (DSC), polarizing optical microscopy (POM), thermogravimetric analysis (TGA), and small angle X-ray scattering (SAXS). The influence of $\mathrm{C} 2$ methylation on the physicochemical properties is studied by comparison with their protonated C2 (ref. 44) and triazolium counterparts. ${ }^{48}$

For convenience, the same compound naming conventions as in previous reports has been used. ${ }^{7,44}$ The compounds are named by the number of carbon atoms in the three alkyl chains at the first, second and third positions of the imidazolium ring. For example, $\left[\mathrm{C}_{12} \mathrm{C}_{1} \mathrm{C}_{5} \mathrm{im}\right][\mathrm{Br}]$, 1-dodecyl-2-methyl-3-pentylimidazolium bromide, as $\mathbf{C}_{\mathbf{1 2}} \mathbf{C}_{\mathbf{1}} \mathbf{C}_{\mathbf{5}}$ and $\left[\mathrm{C}_{12} \mathrm{C}_{1} \mathrm{C}_{6} \mathrm{im}\right][\mathrm{Br}]$, 1-dodecyl-2-methyl-3-hexylimidazolium bromide, as $\mathbf{C}_{\mathbf{1 2}} \mathbf{C}_{\mathbf{1}} \mathbf{C}_{\mathbf{6}}$.

\section{Results and discussion}

\section{Synthesis}

To obtain the different 1-dodecyl-2-methyl-3-alkylimidazolium salts, the respective 2-methylimidazole was reacted with a small excess of dodecylbromide to yield 1-dodecyl-2-methyl-

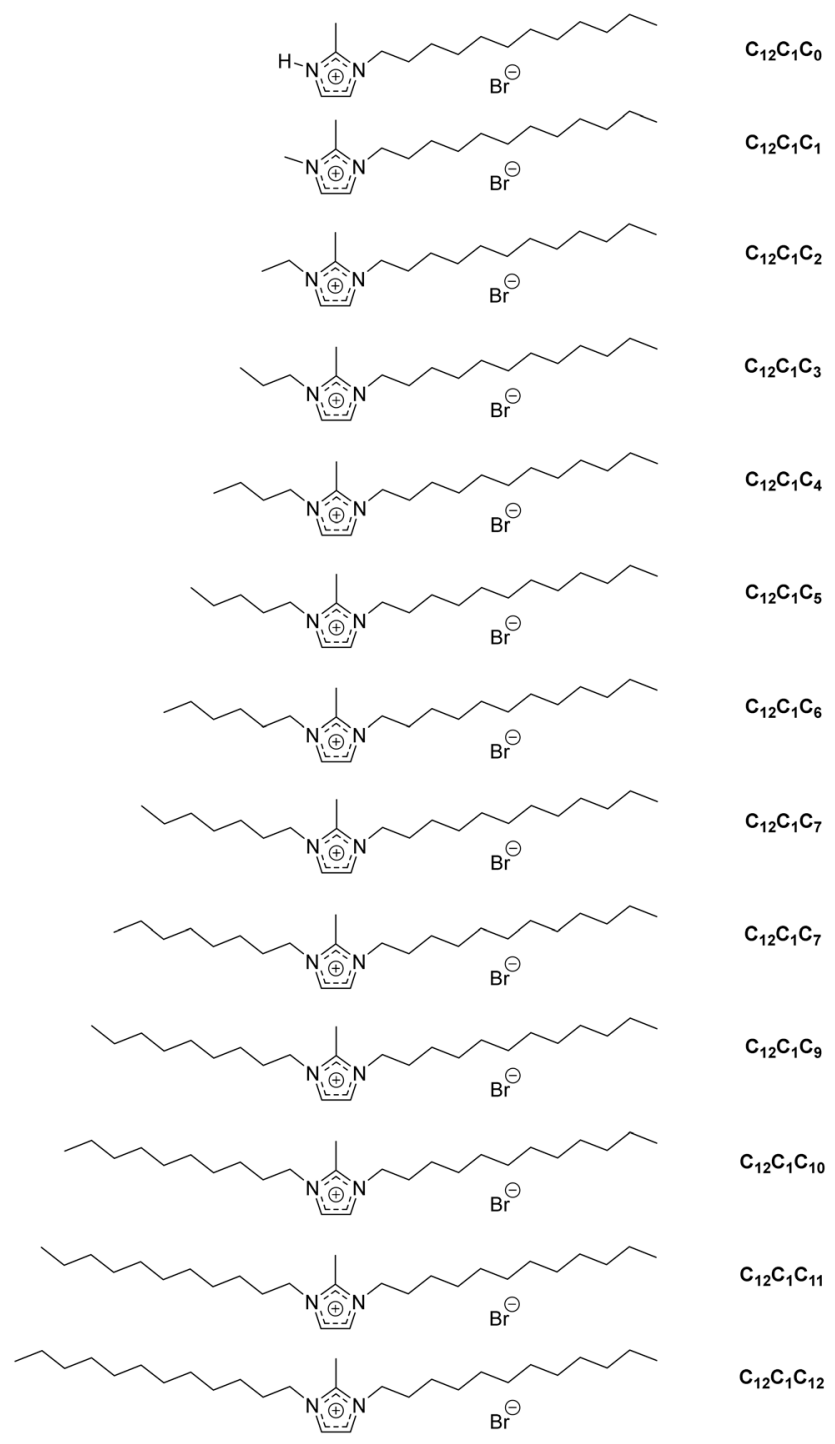

Scheme 1 Different types of ionic liquid cations (and acronyms used for identification) under investigation.

imidazole (Scheme 2). Because of the lack of commercial availability of methyl bromide, the 1,2-dimethylimidazole has been alkylated at the $\mathrm{N}-3$ position with a small excess of dodecylbromide to obtain 1-dodecyl-2,3-dimethylimidazolium $\left(\mathbf{C}_{12} \mathbf{C}_{\mathbf{1}} \mathbf{C}_{\mathbf{1}}\right)$. Compounds $\mathbf{C}_{\mathbf{1 2}} \mathbf{C}_{\mathbf{1}} \mathbf{C}_{\mathbf{2}}-\mathbf{C}_{\mathbf{1 2}} \mathbf{C}_{\mathbf{1}} \mathbf{C}_{\mathbf{1 2}}$ were synthesized by alkylation at the $\mathrm{N}-3$ position with the corresponding alkyl bromide. For the synthesis of compound $\mathbf{C}_{\mathbf{1 2}} \mathbf{C}_{\mathbf{1}} \mathbf{C}_{\mathbf{0}}$, the protonation of the nitrogen has been realized by addition of hydrobromic acid $(\mathrm{HBr})$ at low temperature.

All compounds could be obtained as white crystalline solids apart from $\mathbf{C}_{\mathbf{1 2}} \mathbf{C}_{\mathbf{1}} \mathbf{C}_{\mathbf{5}}$ and $\mathbf{C}_{\mathbf{1 2}} \mathbf{C}_{\mathbf{1}} \mathbf{C}_{\mathbf{7}}$ which were isolated as extremely viscous oils.

\section{Thermal investigations}

To study their thermal behaviour in TGA, DSC, and POM were undertaken. Table 1 lists the decomposition temperatures as recorded by TGA. The decomposition temperatures 


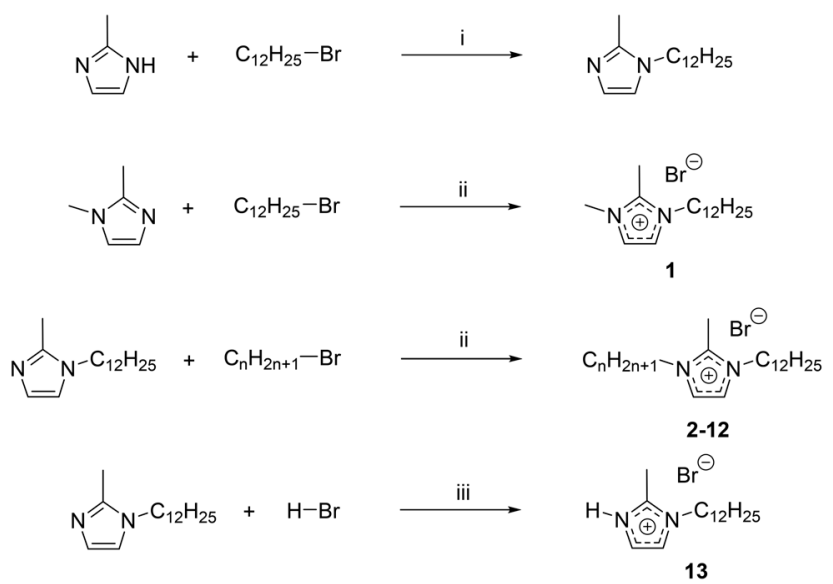

Scheme 2 Syntheses of 1-dodecyl-2-methyl-3-alkylimidazolium $\left(\mathrm{C}_{12} \mathrm{C}_{1} \mathrm{C}_{1}-\mathrm{C}_{12} \mathrm{C}_{1} \mathrm{C}_{12}\right)$ and 1-dodecyl-2-methylimidazolium $\left(\mathrm{C}_{12} \mathrm{C}_{1} \mathrm{C}_{0}\right)$ compounds. i) r.t., $\mathrm{K}_{2} \mathrm{CO}_{3}, \mathrm{THF}$; ii) $80{ }^{\circ} \mathrm{C}, 48 \mathrm{~h}$, acetonitrile; iii) $0{ }^{\circ} \mathrm{C}, 1$ $\mathrm{h}$, diethyl ether.

Table 1 Decomposition temperatures of compounds $\mathrm{C}_{12} \mathrm{C}_{1} \mathrm{C}_{0}-\mathrm{C}_{12} \mathrm{C}_{1} \mathrm{C}_{12}$

\begin{tabular}{ll}
\hline Compound & $T$ decomposition $\left({ }^{\circ} \mathrm{C}\right)$ \\
\hline $\mathbf{C}_{\mathbf{1 2}} \mathbf{C}_{\mathbf{1}} \mathbf{C}_{\mathbf{0}}$ & 262 \\
$\mathbf{C}_{\mathbf{1 2}} \mathbf{C}_{\mathbf{1}} \mathbf{C}_{\mathbf{1}}$ & 273 \\
$\mathbf{C}_{\mathbf{1 2}} \mathbf{C}_{\mathbf{1}} \mathbf{C}_{\mathbf{2}}$ & 266 \\
$\mathbf{C}_{\mathbf{1 2}} \mathbf{C}_{\mathbf{1}} \mathbf{C}_{\mathbf{3}}$ & 268 \\
$\mathbf{C}_{\mathbf{1 2}} \mathbf{C}_{\mathbf{1}} \mathbf{C}_{\mathbf{4}}$ & 271 \\
$\mathbf{C}_{\mathbf{1 2}} \mathbf{C}_{\mathbf{1}} \mathbf{C}_{\mathbf{5}}$ & 269 \\
$\mathbf{C}_{\mathbf{1 2}} \mathbf{C}_{\mathbf{1}} \mathbf{C}_{\mathbf{6}}$ & 269 \\
$\mathbf{C}_{\mathbf{1 2}} \mathbf{C}_{\mathbf{1}} \mathbf{C}_{\mathbf{7}}$ & 270 \\
$\mathbf{C}_{\mathbf{1 2}} \mathbf{C}_{\mathbf{1}} \mathbf{C}_{\mathbf{8}}$ & 266 \\
$\mathbf{C}_{\mathbf{1 2}} \mathbf{C}_{\mathbf{1}} \mathbf{C}_{\mathbf{9}}$ & 259 \\
$\mathbf{C}_{\mathbf{1 2}} \mathbf{C}_{\mathbf{1}} \mathbf{C}_{\mathbf{1 0}}$ & 266 \\
$\mathbf{C}_{\mathbf{1 2}} \mathbf{C}_{\mathbf{1}} \mathbf{C}_{\mathbf{1 1}}$ & 264 \\
$\mathbf{C}_{\mathbf{1 2}} \mathbf{C}_{\mathbf{1}} \mathbf{C}_{\mathbf{1 2}}$ & 263
\end{tabular}

of all compounds are similar within the error limits of measurement and occur around $265 \pm 10{ }^{\circ} \mathrm{C}$. It is remarkable that this series of compounds appears to have a low tendency to take up water, despite having the most hydrogen-bond acceptor and donor sites (due to experimental limitations, it was not possible to transfer the compounds under strictly inert conditions into the thermal analyser. While all samples were handled the same, for some water uptake was observed whilst for others none. See ESI $\dagger$ on the thermal traces). This is an interesting observation as one would expect the hydrophobic character to increase with increasing length of the alkyl chain. Generally speaking, 1,3-dialkylimidazolium ILs exhibit a decomposition temperature higher than that of their analogous triazolium ILs. ${ }^{49}$

Phase transitions were studied in greater detail by employing DSC, POM, SAXS and SXRD (for the latter two, vide infra). Initial phase assignments were made based upon characteristic textures observed in the POM micrographs and confirmed by SAXS and SXRD. The complexity and the different sensitivity to water (which changes the phase behaviour by altering the transition temperatures and observed phases including the formation of lyotropic LC phases) does make it difficult to determine the phase behaviour of the studied compounds from one method alone. However, it is the combination of different methods supports the phase assignments made. The transition temperatures (in ${ }^{\circ} \mathrm{C}$ ), enthalpies (in $\mathrm{J} \mathrm{g}^{-1}$ ) and phase transition assignments as obtained from DSC measurements are listed in Table S3. The samples were first cooled at a thermal ramp of $5{ }^{\circ} \mathrm{C} \mathrm{min}^{-1}$ to $-60{ }^{\circ} \mathrm{C}$ without recording thermal data. During sample preparation contact with the atmosphere and some water uptake could not be completely avoided. Both the first full thermal cycle and the second, showing the anhydrous compounds, are reported. All further thermal cycles were identical with the second unless otherwise stated.

For $\mathbf{C}_{\mathbf{1 2}} \mathbf{C}_{\mathbf{1}} \mathbf{C}_{\mathbf{1}}$ the first heating from $-60{ }^{\circ} \mathrm{C}$ reveals four irreversible phase transitions. First, two solid-solid transitions at $53.1{ }^{\circ} \mathrm{C}\left(\mathrm{Cr} \rightarrow \mathrm{Cr}^{\prime}\right)$ and $67.2{ }^{\circ} \mathrm{C}\left(\mathrm{Cr}^{\prime} \rightarrow \mathrm{Cr}^{\prime \prime}\right)$ were observed, followed by a crystalline solid-liquid crystalline $\left(\mathrm{Cr}^{\prime \prime} \rightarrow \mathrm{SmA}\right)$ transition at $77.4{ }^{\circ} \mathrm{C}$. The liquid crystalline phase was assigned to a smectic A phase (ESI $\dagger$ Fig. S89d). The clearing point $\left(\mathrm{SmA} \rightarrow \mathrm{L}_{\text {iso }}\right.$ ) lies at $148.2{ }^{\circ} \mathrm{C}$. Upon cooling, the transition from isotropic liquid to liquid crystalline $\left(\mathrm{L}_{\text {iso }} \rightarrow \mathrm{SmA}\right)$ is revealed in the cooling scan at $120.5{ }^{\circ} \mathrm{C}$ and a liquid crystalline to crystalline phase $\left(\mathrm{SmA} \rightarrow \mathrm{Cr}^{\prime}\right)$ at $36.2^{\circ} \mathrm{C}$. It appears that under the given cooling rate only a fraction of the sample crystallized. Upon subsequent heating, cold crystallization can be observed at $27.7{ }^{\circ} \mathrm{C}\left(\mathrm{Cr}^{\prime} \rightarrow \mathrm{Cr}\right)$. A comparison of the associated enthalpies shows that indeed cold crystallization at $27.7^{\circ} \mathrm{C}$ lead to a full crystallization of the sample before it melts to a LC state at $81.9{ }^{\circ} \mathrm{C}(\mathrm{Cr} \rightarrow \mathrm{SmA})$. The clearing point $\left(\mathrm{SmA} \rightarrow \mathrm{L}_{\text {iso }}\right.$ ) is observed at $120.0{ }^{\circ} \mathrm{C}$. The reverse transition $\left(\mathrm{L}_{\text {iso }} \rightarrow \mathrm{SmA}\right.$ ) occurs at $120.0^{\circ} \mathrm{C}$ upon cooling. At $36.2^{\circ} \mathrm{C}$ partial crystallization is observed $(\mathrm{SmA} \rightarrow \mathrm{Cr})$. With more thermal cycles the fraction of material that recrystallizes is increased as becomes evident from the phase transition enthalpies, which are $-49.5 \mathrm{~J} \mathrm{~g}^{-1}$ for the first cooling $v s .-54.7$ $\mathrm{J} \mathrm{g}^{-1}$ for the fifth cooling. At the same time, the crystallization peaks, on cooling become more pronounced and sharp revealing a solid-solid transition close to the point of crystallization. The associated cold crystallization peak observed on heating also shows a split into two. All thermal transitions were fully reproducible from the second cooling cycle onwards. A reason why the first heating deviates from all the subsequent cycles is that there is water uptake during sample preparation in ambient air. Similar thermal behaviour has been observed for $\left[\mathrm{C}_{n} \operatorname{mim}\right] \mathrm{Br} \cdot x \mathrm{H}_{2} \mathrm{O},(n=10,12 ; x=0,1){ }^{2}$ There it was observed that water enlarges the mesophase window by pushing the clearing point to higher temperatures. Evaluation of TG data (ESI $\dagger$ ) reveals the presence of $\sim 1$ molecule of $\mathrm{H}_{2} \mathrm{O}$ per formula unit.

The DSC trace of $\mathbf{C}_{\mathbf{1 2}} \mathbf{C}_{\mathbf{1}} \mathbf{C}_{\mathbf{2}}$ reveals a sharp endothermic phase transition at $63.1{ }^{\circ} \mathrm{C}$ during the first heating scan. This can be identified as a melting transition $\left(\mathrm{Cr}^{\prime} \rightarrow \mathrm{L}_{\text {iso }}\right)$. It is preceded by a solid-solid transition $\left(\mathrm{Cr} \rightarrow \mathrm{Cr}^{\prime}\right)$ at $-13.6{ }^{\circ} \mathrm{C}$. Upon cooling crystallization can be observed, but via the transition to a metastable LC phase at $-3.4^{\circ} \mathrm{C}$. Vitrification (transition from liquid to glass) and devitrification (transition from glass to liquid) occur 
around $-28^{\circ} \mathrm{C}$. The subsequent cycles all exhibit the same transitions. Upon heating, a solid-liquid crystalline transition is observed at $10.5{ }^{\circ} \mathrm{C}(\mathrm{Cr} \rightarrow \mathrm{SmA})$ followed by a liquid crystallineisotropic liquid transition at $65.0^{\circ} \mathrm{C}\left(\mathrm{Sm} \rightarrow \mathrm{L}_{\text {iso }}\right)$. It is important to note that several liquid crystalline phases can be seen to compete under the polarizing optical microscope, rendering the identification impossible (ESI, $\dagger$ Fig. S88).

The first heating trace of $\mathbf{C}_{\mathbf{1 2}} \mathbf{C}_{\mathbf{1}} \mathbf{C}_{\mathbf{3}}$ reveals that, aside from a glass transition at $-35.5{ }^{\circ} \mathrm{C}$, there are two non-reversible transitions around $-40{ }^{\circ} \mathrm{C}$ and $10{ }^{\circ} \mathrm{C}$. The second transition was in fact identified to be two overlapping transitions of which the first is the transition to a smectic A phase and the second was the clearing point $\left(28.9^{\circ} \mathrm{C}\right)$. The existence of the mesophase was proven by POM measurements at $25^{\circ} \mathrm{C}$, where smectic A phase characteristic texture could be seen. Upon cooling from the isotropic liquid, only a glass transition around $-35^{\circ} \mathrm{C}$ is observed, which is reversed upon heating at $30.7^{\circ} \mathrm{C}$.

The first heating DSC trace of $\mathbf{C}_{\mathbf{1 2}} \mathbf{C}_{\mathbf{1}} \mathbf{C}_{\mathbf{4}}$ exhibits only one endothermic transition. It is observed at $34.6{ }^{\circ} \mathrm{C}$ and can be attributed to a solid-liquid transition $\left(\mathrm{Cr} \rightarrow \mathrm{L}_{\text {iso }}\right)$. The cooling trace shows a glass transition at $-33.7^{\circ} \mathrm{C}$. Upon subsequent heating devitrification ( $\mathrm{Tg} \rightarrow \mathrm{L}_{\text {iso }}$ ) and cold crystallization $\left(\mathrm{L}_{\text {iso }} \rightarrow \mathrm{Cr}\right.$ ) occur at $-27.2{ }^{\circ} \mathrm{C}$ and $8.2{ }^{\circ} \mathrm{C}$ respectively. The clearing point $\left(\mathrm{Cr} \rightarrow \mathrm{L}_{\text {iso }}\right)$ can then be observed at $35.3^{\circ} \mathrm{C}$. All subsequent thermal cycles are fully reproducible.

Compound $\mathbf{C}_{\mathbf{1 2}} \mathbf{C}_{\mathbf{1}} \mathbf{C}_{\mathbf{5}}$ exhibits a cold crystallization from a smectic A phase at $-30.1{ }^{\circ} \mathrm{C}$ during the first heating, followed by a solid-liquid crystalline transition $(\mathrm{Cr} \rightarrow \mathrm{SmA})$ occurs at $4.8^{\circ} \mathrm{C}$. POM allows identification of the LC phase as a smectic A phase. The clearing point can be found at $51.7^{\circ} \mathrm{C}$. Upon cooling, only a glass transition can be observed at $-37.9^{\circ} \mathrm{C}$. All further cycle only exhibited devitrification and vitrification at $-27.1{ }^{\circ} \mathrm{C}$ and $-37.9{ }^{\circ} \mathrm{C}$ respectively. From this, it can be concluded that crystallization is kinetically hindered.

Compound $\mathbf{C}_{\mathbf{1 2}} \mathbf{C}_{\mathbf{1}} \mathbf{C}_{\mathbf{6}}$ exhibits only one solid-solid transition at $-13.1{ }^{\circ} \mathrm{C}$ before melting into an isotropic liquid at $38.9^{\circ} \mathrm{C}$. The following thermal cycles reveal, similarly to the previous sample, only a glass transition around $-33.0{ }^{\circ} \mathrm{C}$ upon cooling and $-30.5^{\circ} \mathrm{C}$ upon heating.

For compound $\mathbf{C}_{\mathbf{1 2}} \mathbf{C}_{\mathbf{1}} \mathbf{C}_{7}$, a cold recrystallization can be observed upon the first heating at $-12.6^{\circ} \mathrm{C}$, followed by melting to a LC phase at $-1.0^{\circ} \mathrm{C}$. This transition was then later identified by POM to be a smectic $\mathrm{C}$ phase. The final transition is then attributed to a liquid crystalline-isotropic liquid (clearing point) transition. Upon cooling a transition from the isotropic liquid to a smectic $\mathrm{C}$ phase is observed at $53.5^{\circ} \mathrm{C}$. A vitrification can then be observed at $-33.7^{\circ} \mathrm{C}$ which is then reversed upon heating at $-28.6{ }^{\circ} \mathrm{C}$. This is then followed by a liquid crystalline-isotropic liquid transition at $52.6^{\circ} \mathrm{C}$, which is reversed upon cooling at $52.2^{\circ} \mathrm{C}$. These processes are then reproducible in all subsequent cycles. Like for $\mathbf{C}_{\mathbf{1 2}} \mathbf{C}_{\mathbf{1}} \mathbf{C}_{\mathbf{1}}$ TG analysis shows the presence of about one molecule of water per formula unit. Thus, it is expected that the first heating cycle will look different from the following. Like for $\mathbf{C}_{\mathbf{1 2}} \mathbf{C}_{\mathbf{1}} \mathbf{C}_{\mathbf{1}}$, the presence of water moves the clearing point to higher temperatures and enlarges the mesophase window.
Compound $\mathbf{C}_{\mathbf{1 2}} \mathbf{C}_{\mathbf{1}} \mathbf{C}_{\mathbf{8}}$ exhibits two processes of which only one was found to be reversible. The first, non-reversible process, is found at $22.3{ }^{\circ} \mathrm{C}$ and is attributed to the melting point $(\mathrm{Cr} \rightarrow \mathrm{SmC})$. The reversible transition from liquid crystal to liquid ( $\mathrm{Sm} \leftrightharpoons \mathrm{L}_{\text {iso }}$ ) can be found at $106.4{ }^{\circ} \mathrm{C}$ and the reverse process at $109.0{ }^{\circ} \mathrm{C}$. POM observations confirmed the formation of a liquid crystalline phase which was identified as smectic $\mathrm{C}$ phase. This transition is followed by a glass transition at $-39.8{ }^{\circ} \mathrm{C}$. The following cycles all exhibit the same behaviour; a glass transition upon heating at $-36.0{ }^{\circ} \mathrm{C}$ followed by the clearing point $\left(\mathrm{SmC} \rightarrow \mathrm{L}_{\text {iso }}\right)$ at $98.6{ }^{\circ} \mathrm{C}$. The cooling traces then reverse this transition $\left(\mathrm{L}_{\text {iso }} \rightarrow \mathrm{Sm}\right)$ at $100.9^{\circ} \mathrm{C}$ and the vitrification occurs at $-39.8^{\circ} \mathrm{C}$.

The DSC trace for compound $\mathbf{C}_{\mathbf{1 2}} \mathbf{C}_{\mathbf{1}} \mathbf{C}_{\mathbf{9}}$ is very similar to the previous compound's trace. The first process can be found at $33.6{ }^{\circ} \mathrm{C}$ and comprises two overlapping events, of which the latter was identified by POM as a solid to liquid crystalline transition ( $\mathrm{Cr} \rightarrow \mathrm{SmC}$ ) into a smectic $\mathrm{C}$ phase. The clearing point was observed at $122.9{ }^{\circ} \mathrm{C}$. Its reverse transition is observed at $127.9^{\circ} \mathrm{C}$. Vitrification of the smectic $\mathrm{C}$ phase can then be observed at $-33.3{ }^{\circ} \mathrm{C}$. As for the previous compound, the next traces only exhibit a clearing point at $129.1{ }^{\circ} \mathrm{C}$ which is reversed at $127.7^{\circ} \mathrm{C}$, as well as glass transitions around $-33^{\circ} \mathrm{C}$. These processes are highly reproducible.

Compound $\mathbf{C}_{\mathbf{1 2}} \mathbf{C}_{\mathbf{1}} \mathbf{C}_{\mathbf{1 0}}$ exhibits a particular thermal behaviour due to being hydrated, as confirmed by TGA and IRspectroscopy. In fact, during the first heating cycle, four transitions can be observed. The first event can be observed at $-41.2{ }^{\circ} \mathrm{C}$ and is attributed to a solid-solid transition $(\mathrm{Cr} \rightarrow$ $\left.\mathrm{Cr}^{\prime}\right)$. A second transition of this type $\left(\mathrm{Cr}^{\prime} \rightarrow \mathrm{Cr}^{\prime \prime}\right)$ can then be observed at $-16.4{ }^{\circ} \mathrm{C}$. A solid-liquid crystalline phase transition can then be observed at $22.4{ }^{\circ} \mathrm{C}$. The phase was confirmed to be a smectic C phase by POM. The clearing point is observed at $132.9^{\circ} \mathrm{C}$. Upon cooling from the isotropic liquid a smectic $\mathrm{C}$ phase forms at $147.7^{\circ} \mathrm{C}$. A glass transition can also be seen at $-32.9^{\circ} \mathrm{C}$. The ensuing traces exhibit two transitions that are both reversible. Devitrification and vitrification occur at $-31.0^{\circ} \mathrm{C}$ and $-33.9^{\circ} \mathrm{C}$, respectively. The clearing point $\left(\mathrm{SmC} \rightarrow \mathrm{L}_{\text {iso }}\right.$ ) is observed at $140.7{ }^{\circ} \mathrm{C}$ upon heating and is reversed at $145.7^{\circ} \mathrm{C}$ upon cooling.

The first heating cycle for $\mathbf{C}_{\mathbf{1 2}} \mathbf{C}_{\mathbf{1}} \mathbf{C}_{\mathbf{1 1}}$ and $\mathbf{C}_{\mathbf{1 2}} \mathbf{C}_{\mathbf{1}} \mathbf{C}_{\mathbf{1 2}}$ display similar behaviour. In fact, for both compounds, solid-solid transitions $\left(\mathrm{Cr} \rightarrow \mathrm{Cr}^{\prime}\right)$ which involve at least for $\mathbf{C}_{\mathbf{1 2}} \mathbf{C}_{\mathbf{1}} \mathbf{C}_{\mathbf{1 1}}$ two solid forms, can be observed preceding a solid-liquid crystalline transition $\left(\mathrm{Cr}^{\prime} \rightarrow\right.$ SmC) involving two LC states which could not be resolved (as indicated by the peak shape) (Fig. S65 $\dagger$ ) and a clearing point. The first transition is observed at $-19.4{ }^{\circ} \mathrm{C}\left(\mathbf{C}_{\mathbf{1 2}} \mathbf{C}_{\mathbf{1}} \mathbf{C}_{\mathbf{1 1}}\right)$ and $-24.0{ }^{\circ} \mathbf{C}\left(\mathbf{C}_{\mathbf{1 2}} \mathbf{C}_{\mathbf{1}} \mathbf{C}_{\mathbf{1 2}}\right)$. The next events can be found at $33.2{ }^{\circ} \mathrm{C}\left(\mathbf{C}_{\mathbf{1 2}} \mathbf{C}_{\mathbf{1}} \mathbf{C}_{\mathbf{1 1}}\right)$ and $37.9{ }^{\circ} \mathbf{C}\left(\mathbf{C}_{\mathbf{1 2}} \mathbf{C}_{\mathbf{1}} \mathbf{C}_{\mathbf{1 2}}\right)$. Both compounds exhibit clearing points at $127.6{ }^{\circ} \mathrm{C}$ $\left(\mathbf{C}_{12} \mathbf{C}_{\mathbf{1}} \mathbf{C}_{11}\right)$ and $140.3{ }^{\circ} \mathrm{C}\left(\mathbf{C}_{\mathbf{1 2}} \mathbf{C}_{\mathbf{1}} \mathbf{C}_{\mathbf{1 2}}\right)$. In fact, $\mathbf{C}_{\mathbf{1 2}} \mathbf{C}_{\mathbf{1}} \mathbf{C}_{\mathbf{1 1}}$ exhibits a reversal of its clearing point at $158.4{ }^{\circ} \mathrm{C}$ followed by a partial recrystallization at $-16.4{ }^{\circ} \mathrm{C} . \mathbf{C}_{\mathbf{1 2}} \mathbf{C}_{\mathbf{1}} \mathbf{C}_{\mathbf{1 2}}$ displays a similar behaviour as it reverses its clearing point at $166.6^{\circ} \mathrm{C}$ and recrystallizes at $-11.8^{\circ} \mathrm{C}$. 
The second heating traces of the two compounds differ slightly. $\mathbf{C}_{\mathbf{1 2}} \mathbf{C}_{\mathbf{1}} \mathbf{C}_{\mathbf{1 1}}$ does not display its solid-solid transition any longer and only shows two reversible processes identified as a melting transition at $-27.4{ }^{\circ} \mathrm{C}$ and a clearing point at $152.8^{\circ} \mathrm{C}$. The transitions are then reversed upon cooling at $158.4{ }^{\circ} \mathrm{C}$ and $-18.4{ }^{\circ} \mathrm{C}$ respectively. These process are then highly reproducible.

$\mathbf{C}_{\mathbf{1 2}} \mathbf{C}_{\mathbf{1}} \mathbf{C}_{\mathbf{1 2}}$ on the other hand displays a very similar behaviour as in its first trace, albeit with a lower enthalpy content, pointing to kinetically hindered effects. A solid-solid transition $\left(\mathrm{Cr} \rightarrow \mathrm{Cr}^{\prime}\right)$ is found at $-18.5^{\circ} \mathrm{C}$ followed by a solid-liquid crystalline transition $\left(\mathrm{Cr}^{\prime} \rightarrow \mathrm{SmC}\right)$ at $39.2^{\circ} \mathrm{C}$ and a clearing point at $161.5^{\circ} \mathrm{C}$. All transitions are reversible and appear at $165.9^{\circ} \mathrm{C}\left(\mathrm{L}_{\text {iso }} \rightarrow \mathrm{SmC}\right)$ and $-11.8^{\circ} \mathrm{C}(\mathrm{SmC} \rightarrow \mathrm{Cr})$. These processes are then highly reproducible.

Compound $\mathbf{C}_{\mathbf{1 2}} \mathbf{C}_{\mathbf{1}} \mathbf{C}_{\mathbf{0}}$ exhibits four events in its first heating cycle. The first at $-10.1^{\circ} \mathrm{C}$ is attributed to a solid-solid transition $\left(\mathrm{Cr} \rightarrow \mathrm{Cr}^{\prime}\right)$, and two additional solid-solid transitions ( $\mathrm{Cr}$ $\left.\rightarrow \mathrm{Cr}^{\prime \prime}\right)$ at $22.3{ }^{\circ} \mathrm{C}$ and $\left(\mathrm{Cr}^{\prime \prime} \rightarrow \mathrm{Cr}^{\prime \prime \prime}\right)$ at $28.8{ }^{\circ} \mathrm{C}$ can be distinguished. The final event at $84.0{ }^{\circ} \mathrm{C}$ was identified as a solidliquid transition $\left(\mathrm{Cr}^{\prime \prime \prime} \rightarrow \mathrm{L}_{\text {iso }}\right)$. Upon cooling, at $67.0{ }^{\circ} \mathrm{C}$, the clearing point is reversed $\left(\mathrm{L}_{\text {iso }} \rightarrow \mathrm{Cr}^{\prime \prime \prime}\right)$ followed by two solidsolid transitions at $59.7{ }^{\circ} \mathrm{C}\left(\mathrm{Cr}^{\prime \prime \prime} \rightarrow \mathrm{Cr}^{\prime \prime}\right)$ and $41.7^{\circ} \mathrm{C}\left(\mathrm{Cr}^{\prime \prime} \rightarrow\right.$ $\left.\mathrm{Cr}^{\prime}\right)$. Upon subsequent heating cold crystallization occurs at $24.7^{\circ} \mathrm{C}$ before melting at $85.3^{\circ} \mathrm{C}$. Upon cooling the trace follows the first trace.

Compounds $\mathbf{C}_{\mathbf{1 2}} \mathbf{C}_{\mathbf{1}} \mathbf{C}_{\mathbf{4}}, \mathbf{C}_{\mathbf{1 2}} \mathbf{C}_{\mathbf{1}} \mathbf{C}_{\mathbf{6}}$ and $\mathbf{C}_{\mathbf{1 2}} \mathbf{C}_{\mathbf{1}} \mathbf{C}_{\mathbf{0}}$ do not form liquid crystalline phases. A similar observation for the 1-dodecyl-3-alkylimidazolium based bromide salts with ethyland hexyl-unit was reported. ${ }^{44}$

For $\mathbf{C}_{\mathbf{1 2}} \mathbf{C}_{\mathbf{1}} \mathbf{C}_{\mathbf{0}}$ the melting point is almost the same as for its non-methylated counterpart. However, for a chain length of $\mathrm{C}_{n}(n \geq 8)$, the opposite is observed. The reason for this increase has previously been attributed to a reduction in entropy. ${ }^{11,23,50}$ The triazolium analogues seem to exhibit a lower melting point when the chain length is $\mathrm{C}_{n}(n \leq 7)$ with the exception of $\mathrm{C}_{1}$. Longer chain lengths usually exhibit the highest melting point of all the compounds.

In general, the $\mathrm{Sm} \rightleftarrows \mathrm{L}_{\text {iso }}$ transitions are reversible and can be observed with similar enthalpy values in the cooling scans of each liquid crystalline sample except $\mathbf{C}_{\mathbf{1 2}} \mathbf{C}_{\mathbf{1}} \mathbf{C}_{5}$. In contrast, the $\mathrm{Cr} \rightarrow \mathrm{Sm}$ transitions could almost only be observed in the first heating scans and could not be considered reversible. Some materials show a cold crystallization process in the second heating scan preceding the melting transitions (e.g. $\mathbf{C}_{\mathbf{1 2}} \mathbf{C}_{\mathbf{1}} \mathbf{C}_{\mathbf{4}}$ ), whereas in others, no crystallization is observed (e.g. $\mathbf{C}_{\mathbf{1 2}} \mathbf{C}_{\mathbf{1}} \mathbf{C}_{\mathbf{3}}$ and $\mathbf{C}_{\mathbf{1 2}} \mathbf{C}_{\mathbf{1}} \mathbf{C}_{\mathbf{5}}$ ). In addition, the enthalpy values of the $\mathrm{Cr} \rightarrow \mathrm{Sm}$ transitions in the further heating cycles are significantly lower than the enthalpy values from the first heating cycles, while the enthalpy values for $\mathrm{Sm} \rightarrow \mathrm{L}_{\text {iso }}$ phase transition do not vary. The previously mentioned observations indicate that the crystallization kinetics are relatively slow and inhibited by the rapid cooling rate. Furthermore, the enthalpy values of $\mathrm{Sm} \rightarrow \mathrm{L}_{\text {iso }}$ transitions for the liquid crystalline compounds in this series are very similar to those of the liquid crystalline 1-dodecyl-3-alkylimidazolium bromides. In contrast, the enthalpy values of $\mathrm{Cr} \rightarrow \mathrm{Sm}$ transitions for the liquid crystalline compounds are significantly higher than for the liquid crystalline 1-dodecyl-3alkylimidazolium compounds. For example, $\left[\mathrm{C}_{12} \mathrm{C}_{12} \mathrm{im}\right][\mathrm{Br}]$ undergoes a $\mathrm{Cr} \rightarrow \mathrm{Sm}$ transition with an enthalpy $\Delta H=26.3 \mathrm{~J}$ $\mathrm{g}^{-1}$, whereas $\mathbf{C}_{\mathbf{1 2}} \mathbf{C}_{\mathbf{1}} \mathbf{C}_{\mathbf{1 2}}$ undergoes a $\mathrm{Cr} \rightarrow$ Sm transition with an enthalpy $\Delta H=72.31 \mathrm{~J} \mathrm{~g}^{-1}$. Therein, according to the results obtained from quantum chemical calculations by Hunt, ${ }^{11}$ the methylation on $\mathrm{C} 2$ position inhibits the rotation of the alkyl side chains, which leads to a decreased entropy. In the case of ILs with bromide anions and short alkyl side chains $(n=2-4)$, no decrease in the enthalpy was observed in the previous report. As already mentioned, for the long-chain containing ILs in the present study, a significant increase in transition enthalpies after the $\mathrm{C} 2$ methylation was found. The phase transition temperature is described by the quotient of transition enthalpy and entropy. Therefore, the reduction in the entropy values and the increasing enthalpy values lead to the increase of melting point. ${ }^{10,51}$

The specific changes in the melting points displayed in Fig. 1 show an inverse relation with the non-methylated compounds. In fact, the melting points are alternating from high to low depending on the parity of the number of carbons within the chain. For the non-methylated compounds, the melting point follows the trend discovered for alkanedicarboxylic acids in which an even number of carbon atoms would always result in a slightly higher melting point. ${ }^{52}$ The opposite is observed for the methylated compounds. The characteristic changes in the clearing point follow the same trend for our observations of $\mathrm{C} 2$ protonated 1-dodecyl-3alkylimidazolium bromides ${ }^{44}$ and triazolium bromides. ${ }^{48}$ The clearing points decrease with increasing $n$ for $n=1-3$. For $n=$ $4-6$, a slight increase of clearing points can be observed. For $n \geq 7$, the clearing points increase rapidly with rising $n$. Interestingly, 1-dodecyl-2-methyl-3-alkylimidazolium salts have much higher clearing points and therefore wider mesophase temperature ranges than their 1-dodecyl-3-

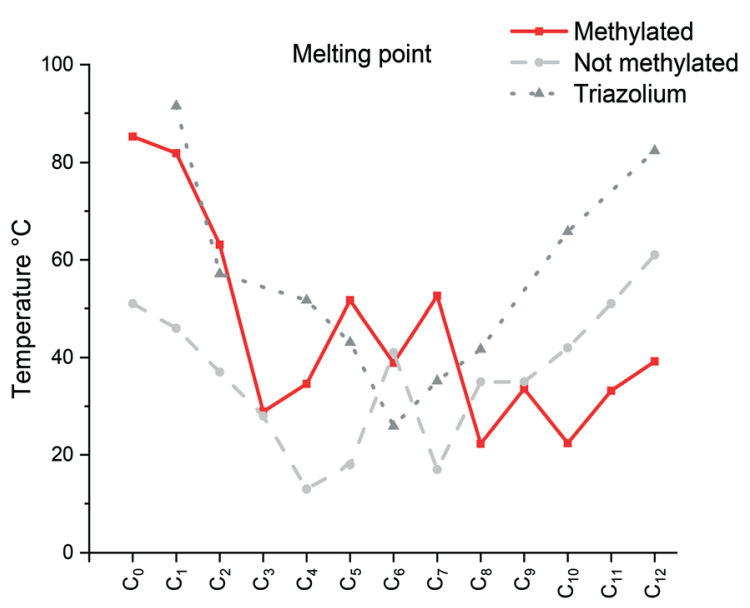

Fig. 1 Comparison of the melting point $\left(\mathrm{Cr} \rightarrow \mathrm{Sm} / \mathrm{L}_{\text {iso }}\right)$ of the $\left[\mathrm{C}_{12} \mathrm{C}_{1} \mathrm{C}_{n} \mathrm{Im}\right][\mathrm{Br}]$ (methylated), $\left[\mathrm{C}_{12} \mathrm{C}_{n} \mathrm{Im}\right][\mathrm{Br}]$ (not methylated) ${ }^{42}$ and $\left[\mathrm{C}_{12} \mathrm{C}_{n} \mathrm{Tr}\right][\mathrm{Br}]\left(1,2,3\right.$-triazolium). ${ }^{46}$ 
alkylimidazolium bromides and triazolium counterparts (Fig. 2). In fact, for compound $\mathbf{C}_{\mathbf{1 2}} \mathbf{C}_{\mathbf{1}} \mathbf{C}_{\mathbf{1 2}}$, the triazolium bromide and 1,3-didodecylimidazolium exhibit an almost identical clearing point. In general, it is noted that the removal of the most acidic proton on the imidazole (proton on the C2 position) dramatically increases both the melting and clearing point of the salt.

The falling trend indicates structural disorganization by insertion of short alkyl chains into well-ordered dodecyl chains. The short alkyl chain $(n \leq 3)$ hinders the close packing of molecules, whereas parallel chain packing maximizes the van der Waals forces between the dodecyl chains for $\mathbf{C}_{\mathbf{1 2}} \mathbf{C}_{\mathbf{1}} \mathbf{C}_{\mathbf{1 2}}$. It is well-known that the melting point can also be affected by the degree of interdigitation in the solid-state. A smaller $d$ value in the crystalline state indicates a high extent of alkyl chain interdigitation, which leads to a high melting point. The trend in the melting transitions for $4 \leq n \leq 12$ confirms this statement. In addition, it has been reported that odd length chains are more likely to adopt an all-trans configuration, ${ }^{53}$ resulting in a higher melting point for compound $\mathbf{C}_{\mathbf{1 2}} \mathbf{C}_{\mathbf{1}} \mathbf{C}_{\mathbf{9}}$ than its immediate neighbours with even lengths of $n$ (Fig. 3).

\section{Crystal structures}

Single crystals of $\mathbf{C}_{\mathbf{1 2}} \mathbf{C}_{\mathbf{1}} \mathbf{C}_{\mathbf{1}}$ and $\mathbf{C}_{\mathbf{1 2}} \mathbf{C}_{\mathbf{1}} \mathbf{C}_{\mathbf{0}}$ were obtained by recrystallization from ethyl acetate. The monohydrate of $\mathbf{C}_{12} \mathbf{C}_{\mathbf{1}} \mathbf{C}_{12}$, could be crystallized from a dichloromethane solution of the anhydrous compound by isothermal evaporation in air at room temperature. All crystals, as a rule, appeared in the form of thin plates.

Compound $\mathbf{C}_{\mathbf{1 2}} \mathbf{C}_{\mathbf{1}} \mathbf{C}_{\mathbf{0}}$ crystallizes triclinic $(P \overline{1}$, No. 2$)$ and contains two asymmetric units in the unit cell (Fig. 4a). The dodecylalkyl chain of the imidazolium cation adopts an alltrans conformation and forms an angle with the methylimidazolium core plane (defined as the angle between the

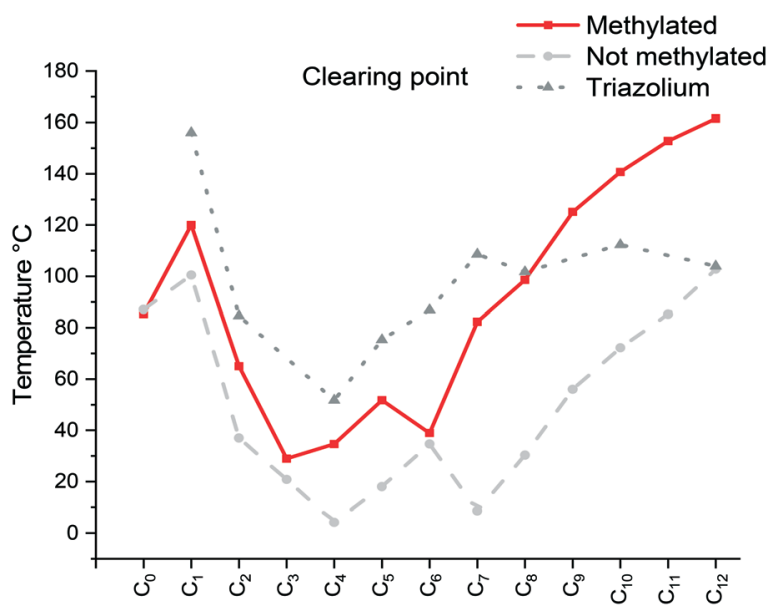

Fig. 2 Comparison of the clearing point taken from the 2nd heating $\left(\mathrm{Cr} / \mathrm{Sm} \rightarrow \mathrm{L}_{\text {iso }}\right)$ of the $\left[\mathrm{C}_{12} \mathrm{C}_{1} \mathrm{C}_{n} \mathrm{Im}\right][\mathrm{Br}]$ (methylated), $\left[\mathrm{C}_{12} \mathrm{C}_{n} \mathrm{Im}\right][\mathrm{Br}]$ (nonmethylated $)^{42}$ and $\left[\mathrm{C}_{12} \mathrm{C}_{n} \mathrm{Tr}\right][\mathrm{Br}](\mathrm{Tr}=\text { triazolium })^{46}$ compounds $\mathrm{C}_{12} \mathrm{C}_{1} \mathrm{C}_{5}$ and $\mathrm{C}_{12} \mathrm{C}_{1} \mathrm{C}_{6}$ a problem as only glass transitions observed.

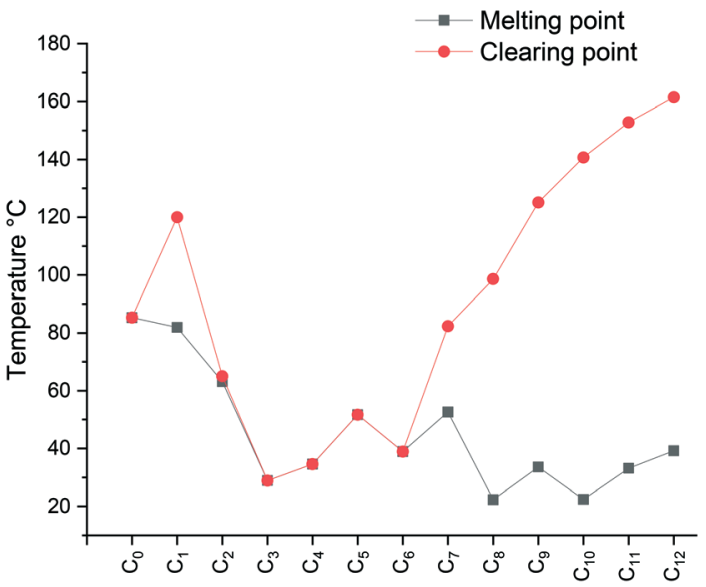

Fig. 3 Plot of melting point and clearing point temperature as a function of compound number. The melting points are plotted in black and clearing points in red. The data were taken from the onset temperature from the second DSC heating scans.

imidazolium ring centroid and the terminal $\mathrm{C}$ atom of alkyl chain) of $152.2^{\circ}$. The chain is not completely straight and shows a slight bow originating from a dihedral angle of $172.0^{\circ}$ along C6-C10-C16. The dodecyl tails form parallel hydrophobic stacks with end-to-end packing (i.e. no alkyl chain interdigitation is observed) resulting in bilayer lamellar structure. The imidazolium head groups are parallel to each other, adopting a direct face-to-face conformation (Fig. 4). They tilt with respect to the $a b$ plane, forming a $51.8^{\circ}$ angle, while the alkyl chains form a $67.4^{\circ}$ angle with the $a b$ plane. The amphiphilic character of the cation results in a separation of polar and non-polar regions in the crystalline packing. The nonpolar regions are formed by the alkyl tail groups, held

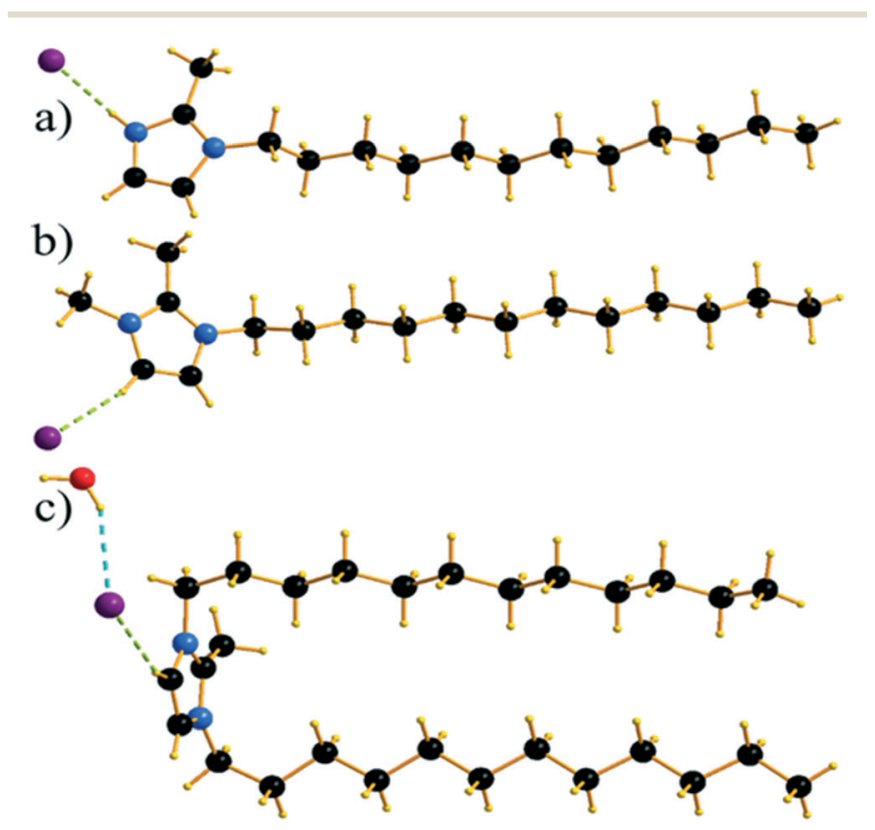

Fig. 4 Asymmetric units of $\mathrm{C}_{12} \mathrm{C}_{1} \mathrm{C}_{0}$ (a), $\mathrm{C}_{12} \mathrm{C}_{1} \mathrm{C}_{1}$ (b) and $\mathrm{C}_{12} \mathrm{C}_{1} \mathrm{C}_{12} \cdot \mathrm{H}_{2} \mathrm{O}$ (c). 
together by van der Waals interactions. The polar parts are constituted of charged methylimidazolium head groups and bromide anions exhibiting rather strong $\pi-\pi\left(d_{\mathrm{Cg}-\mathrm{Cg}}=3.79 \AA\right.$, offset $1.63 \AA$ ) and $\mathrm{Br} \cdots \mathrm{H}$ interactions (Fig. 5). Both of them are responsible for strong intralayer bonding. Each methylimidazolium cation is further linked to bromide anions through non-classical hydrogen bonds. The latter are also observed between the bromide anions and practically all hydrogen atoms on the alkyl chain, though involving different molecules leading to a 3D network. The hydrogen bonds show a distance range of 2.4-3.1 $\AA$ (Table 2) where $2.4 \AA$ stands solely for the $\mathrm{Br} \cdots \mathrm{H}-\mathrm{N}$ pairs and all others are significantly longer (Fig. 6).

Compound $\mathbf{C}_{\mathbf{1 2}} \mathbf{C}_{\mathbf{1}} \mathbf{C}_{\mathbf{1}}$ crystallizes in the monoclinic space group $P 2_{1} / c$ (No. 14) with four formula units in the unit cell. The asymmetric unit contains a $\left[\mathrm{C}_{12} \mathrm{C}_{1} \mathrm{C}_{1} \mathrm{im}\right]^{+}$cation and a bromide anion (Fig. 4b). Both the $\mathrm{C}$ atoms from the methyl groups and the starting $\mathrm{C}$ atom in the dodecyl chain are located in the imidazolium core plane. In contrast to $\mathbf{C}_{\mathbf{1 2}} \mathbf{C}_{\mathbf{1}} \mathbf{C}_{\mathbf{0}}$, the dodecyl chains are straight and form interdigitated stacks, while the angle between the dodecyl chain and methylimidazolium plane is slightly reduced - from $152.2^{\circ}$ to $144.5^{\circ}$. Interdigitation of the alkyl chains is observed in the (101) plane. The cations stack in such a way that their dodecyl chains alternate orientation in neighbouring layers, hence forming a bilayer structure. When viewed along the crystallographic $c$-axis, the polar head groups line up in a row, with adjacent alkyl tails tilted in different directions, forming a herringbone-like structure (Fig. 7). The angle between the adjacent alkyl chain planes is $\sim 32^{\circ}$. Instead of classic $\pi-\pi$ interactions between the imidazole cores observed in $\mathbf{C}_{\mathbf{1 2}} \mathbf{C}_{\mathbf{1}} \mathbf{C}_{\mathbf{0}}, \mathbf{C}_{\mathbf{1 2}} \mathbf{C}_{\mathbf{1}} \mathbf{C}_{\mathbf{1}}$ exhibits solely $\mathrm{CH}-\pi$ interactions $\left(d_{\mathrm{CH}-\mathrm{Cg}}=\right.$ $3.49, d_{\mathrm{Cg}-\mathrm{Cg}}=4.47 \AA$, offset $3.05 \AA$ ). Hydrogen bonds are observed between the bromide ion and hydrogen atoms of four neighbouring methylimidazolium head groups as well as a $\mathrm{C}-\mathrm{H} \cdots \mathrm{Br}$ interaction at the terminal $\mathrm{CH}_{3}$ group of a dodecyl chain. In contrast to $\mathbf{C}_{\mathbf{1 2}} \mathbf{C}_{\mathbf{1}} \mathbf{C}_{\mathbf{0}}$ and perhaps due to the absence of $\mathrm{N}-\mathrm{H} \cdots \mathrm{Br}$ interactions, the bonds length distribution is more regular, starting from $2.77 \AA$, and the role of hydrogenbonding in this structure is less significant. Non-classical hydrogen-bonds with still reasonable distances can be observed solely with the methyl/methylene groups of the carbon chains. Presumably, hydrogen-bonding could be the main

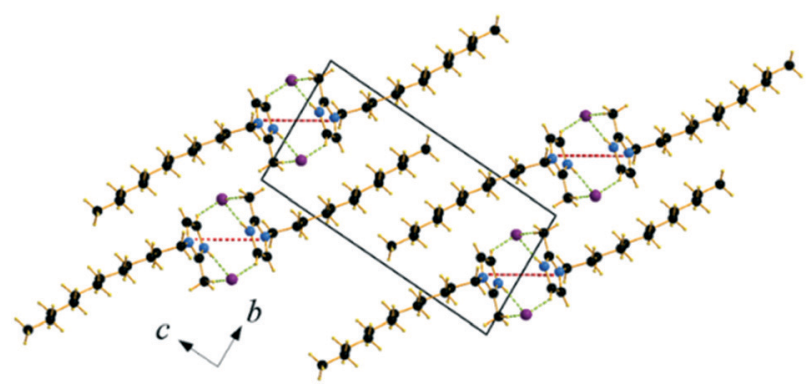

Fig. 5 Packing diagram of $\mathrm{C}_{12} \mathrm{C}_{1} \mathrm{C}_{0}$. Projection on the bc plane. $\mathrm{C}_{\mathrm{g}}-\mathrm{C}_{\mathrm{g}}$ contacts are shown by red and $\mathrm{Br} \cdots \mathrm{H}$ bonds by green dashed lines.
Table 2 Shortest (below $3 \AA$ A hydrogen-bonds in $\mathrm{C}_{12} \mathrm{C}_{1} \mathrm{C}_{0}, \mathrm{C}_{12} \mathrm{C}_{1} \mathrm{C}_{1}$ and $\mathrm{C}_{12} \mathrm{C}_{1} \mathrm{C}_{12} \cdot \mathrm{H}_{2} \mathrm{O}$

\begin{tabular}{lllll}
\hline & $\mathrm{D}-\mathrm{A} / \AA$ & $\mathrm{D}-\mathrm{H} / \AA$ & $\mathrm{H} \cdots \mathrm{A} / \AA$ & $\mathrm{D}-\mathrm{H} \cdots \mathrm{A} /{ }^{\circ}$ \\
\hline $\mathbf{C}_{\mathbf{1 2}} \mathbf{C}_{\mathbf{1}} \mathbf{C}_{\mathbf{0}}$ & & & & \\
$\mathrm{N} 1-\mathrm{H} \cdots \mathrm{Br}$ & 3.232 & 0.84 & 2.393 & 174.2 \\
$\mathrm{C} 1-\mathrm{H} \cdots \mathrm{Br}$ & 3.703 & 0.93 & 2.880 & 148.2 \\
$\mathrm{C} 4-\mathrm{H} \cdots \mathrm{Br}$ & 3.768 & 0.96 & 2.820 & 169.5 \\
$\mathrm{C} 5-\mathrm{H} \cdots \mathrm{Br}$ & 3.739 & 0.97 & 3.001 & 133.9 \\
$\mathrm{C} 11-\mathrm{H} \cdots \mathrm{Br}$ & 3.950 & 0.97 & 2.995 & 169.1 \\
$\mathrm{C}_{\mathbf{1 2}} \mathbf{C}_{\mathbf{1}} \mathbf{C}_{\mathbf{1}}$ & & & & \\
$\mathrm{C} 17-\mathrm{H} \cdots \mathrm{Br}$ & 3.676 & 0.93 & 2.769 & 165.1 \\
$\mathrm{C} 16-\mathrm{H} \cdots \mathrm{Br}$ & 3.646 & 0.93 & 2.771 & 157.3 \\
$\mathrm{C} 14-\mathrm{H} \cdots \mathrm{Br}$ & 3.791 & 0.96 & 2.948 & 147.1 \\
$\mathrm{C}_{\mathbf{1 2}} \mathbf{C}_{\mathbf{1}} \mathbf{C}_{\mathbf{1 2}} \cdot \mathrm{H}_{2} \mathrm{O}$ & & & & \\
$\mathrm{O} w-\mathrm{H} \cdots \mathrm{Br}$ & 3.332 & 0.90 & 2.438 & 169.7 \\
$\mathrm{O} w-\mathrm{H} \cdots \mathrm{Br}$ & 3.387 & 0.90 & 2.559 & 154.1 \\
$\mathrm{C} 4-\mathrm{H} \cdots \mathrm{Br}$ & 3.790 & 0.93 & 2.937 & 153.2 \\
$\mathrm{C} 5-\mathrm{H} \cdots \mathrm{Br}$ & 3.916 & 0.93 & 2.960 & 168.4 \\
$\mathrm{C} 1-\mathrm{H} \cdots \mathrm{Br}$ & 3.907 & 0.97 & 2.970 & 165.5 \\
$\mathrm{C} 1-\mathrm{H} \cdots \mathrm{Br}$ & 3.918 & 0.97 & 2.972 & 169.1 \\
$\mathrm{C} 3-\mathrm{H} \cdots \mathrm{O}$ & 3.223 & 0.93 & 2.327 & 161.6 \\
& & & &
\end{tabular}

reason why $\mathbf{C}_{\mathbf{1 2}} \mathbf{C}_{\mathbf{1}} \mathbf{C}_{\mathbf{1}}$ does not crystallize isostructurally with the analogous 1-dodecyl-3-methyl-1,2,3-triazolium bromide. ${ }^{48}$ The most distinct difference is that the packing of the alkylchains is missing the herringbone structure, but exhibit a packing more similar to 1-dodecyl-3-methylimidazolium bromide monohydrate. ${ }^{1,2}$ In addition, the steric hindrance caused by the addition of the methyl group hinders the packing into the same arrangements as the triazolium analogue. Both of these structural differences also help in explaining the dissimilarities in their thermal properties. In fact, the triazolium exhibits more interdigitation which promotes a larger liquid crystalline window.

Though the attempts to obtain sufficient quality crystals of the anhydrous $\mathbf{C}_{\mathbf{1 2}} \mathbf{C}_{\mathbf{1}} \mathbf{C}_{\mathbf{1 2}}$ have so far been unsuccessful, both anhydrous and monohydrate $\left[\mathrm{C}_{12} \mathrm{C}_{1} \mathrm{C}_{12} \mathrm{im}\right][\mathrm{Br}] \cdot \mathrm{H}_{2} \mathrm{O}$ $\left(\mathbf{C}_{\mathbf{1 2}} \mathbf{C}_{\mathbf{1}} \mathbf{C}_{\mathbf{1 2}} \cdot \mathrm{H}_{2} \mathrm{O}\right)$ compounds show similar layer distances according to SAXS-measurements, vide infra. Therefore, we believe the anhydrous compound would present similar characteristics in its structure. $\mathbf{C}_{\mathbf{1 2}} \mathbf{C}_{\mathbf{1}} \mathbf{C}_{\mathbf{1 2}} \cdot \mathrm{H}_{2} \mathrm{O}$ crystallizes as colourless thin needle-shaped crystals and in the triclinic space group $P \overline{1}$ (No. 2) with two formula units in the unit

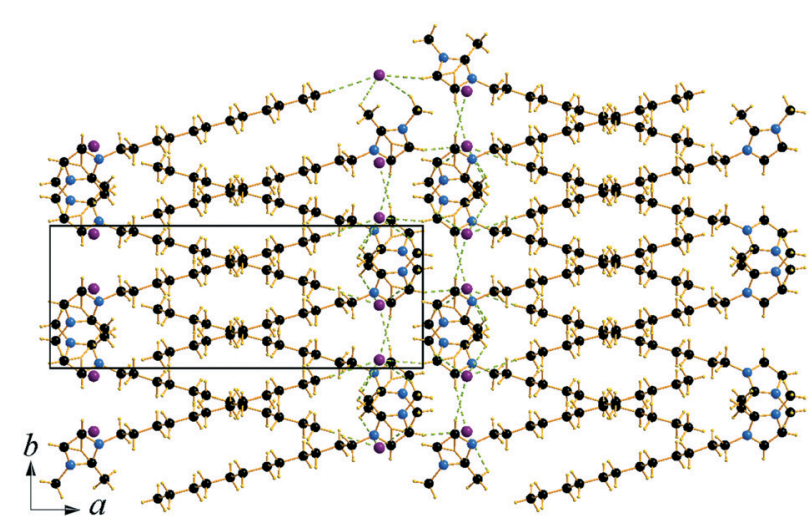

Fig. 6 Packing diagram of $\mathrm{C}_{12} \mathrm{C}_{1} \mathrm{C}_{1}$. Projection on the $a b$ plane. 


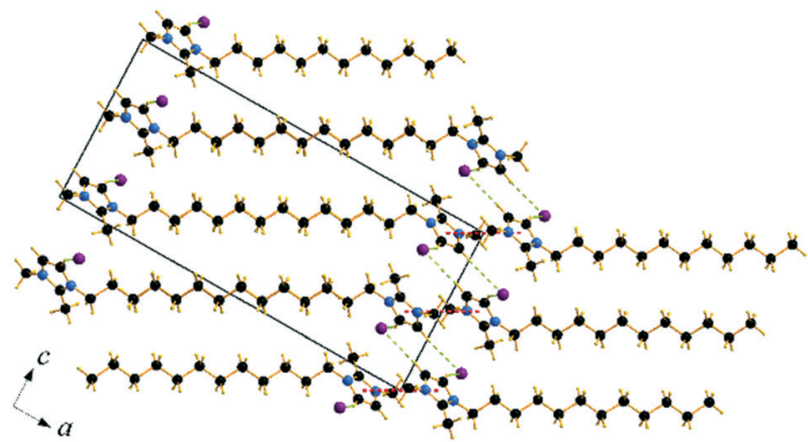

Fig. 7 Packing diagram of $\mathrm{C}_{12} \mathrm{C}_{1} \mathrm{C}_{1}$. Projection on the ac plane. $\mathrm{Br} \cdots \mathrm{H}$ bonds are shown by green dashed lines.

cell. The asymmetric unit contains a $\left[\mathrm{C}_{12} \mathrm{C}_{1} \mathrm{C}_{12} \mathrm{im}\right]^{+}$cation, a bromide anion, and a water molecule (Fig. 4c). An exclusively U-shaped conformation of the cations is observed in the crystal packing. Both $N$-alkyl chains are approximately orthogonal to the methylimidazolium plane and point in the same direction. The methylimidazolium cores are almost parallel to the $a b$-plane. The U-shape can be defined by the angles formed around the first $\mathrm{C}$ atom of the dodecyl chain, between the $\mathrm{N}$ atom from the methylimidazolium ring and the terminal $\mathrm{C}$ atom of the dodecyl chain, and are measured as $93.6^{\circ}$ and $97.6^{\circ}$ for the two dodecyl chains, respectively. Both dodecyl chains adopt an all-trans conformation being almost overlapped in the projection approximately on the ac plane. A slight shift is observed only for the first three carbon positions that gradually decreases and becomes invisible for the fourth one. Such a U-shaped conformation has been previously observed for benzimidazolium halides ${ }^{18}$ and 1,3-didodecylimidazolium with $\left[\mathrm{N}(\mathrm{CN})_{2}\right]^{-}$and $\left[\mathrm{C}(\mathrm{CN})_{3}\right]^{-}$as counter ions. ${ }^{54}$

The cation head groups are held in a row connected side by side through strong $\pi-\pi$ interactions $\left(d_{\mathrm{Cg}-\mathrm{Cg}}=3.70 \AA\right.$, offset $1.44 \AA$ ) and $\mathrm{CH} \cdots \mathrm{Br}$ hydrogen-bonds, while all the dodecyl chains point in the same direction (Fig. 9). Two rows of cations stack in such a way that their dodecyl chains alternate orientational direction in neighbouring layers, hence forming

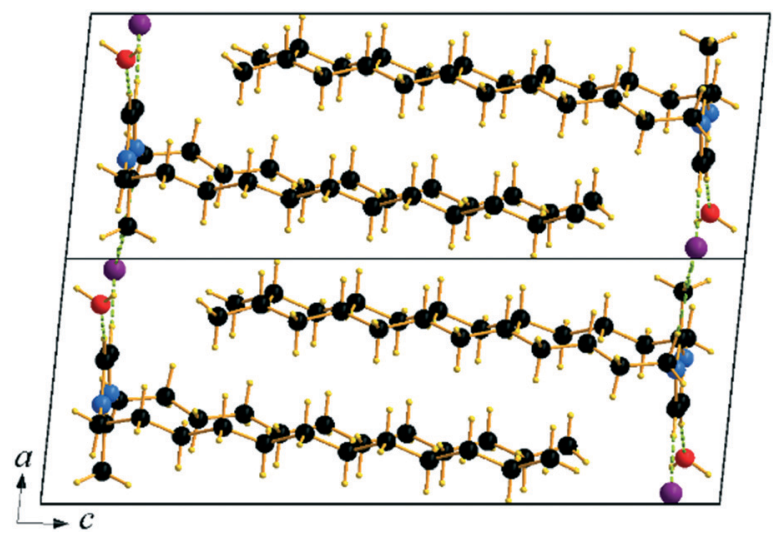

Fig. 8 Packing diagram of $\mathrm{C}_{12} \mathrm{C}_{1} \mathrm{C}_{12} \cdot \mathrm{H}_{2} \mathrm{O}$. Projection on the ac plane.

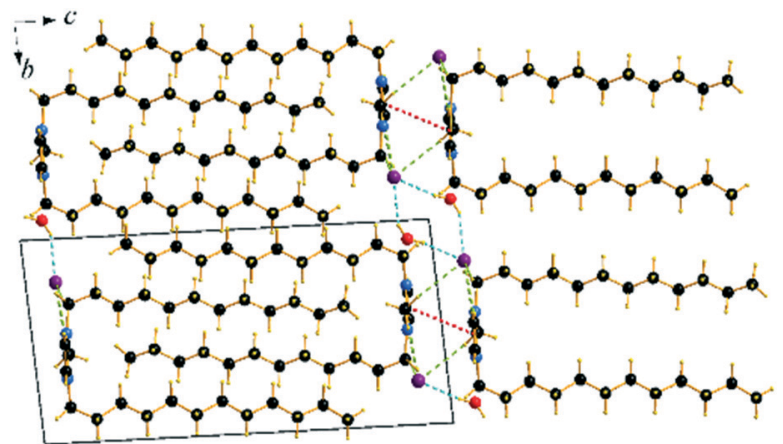

Fig. 9 Packing diagrams of $\mathrm{C}_{12} \mathrm{C}_{1} \mathrm{C}_{12} \cdot \mathrm{H}_{2} \mathrm{O}$. Projection on the bc plane. $\mathrm{C}_{\mathrm{g}}-\mathrm{C}_{\mathrm{g}}$ contacts are shown by red and $\mathrm{Br} \cdots \mathrm{H}$ bonds by green and $\mathrm{O} \cdots \mathrm{H}$ by blue dashed lines.

a bilayer structure. The dodecyl chains interdigitate in rows and are aligned approximately with the crystallographic $c$-axis (tilt $10.1^{\circ}$ from the $a b$-plane normal). The interdigitated cation stacks form a bilayer with a thickness of $20.5 \AA$ (Fig. 8), which in turn form a lamellar structure. Similarly to $\mathbf{C}_{\mathbf{1 2}} \mathbf{C}_{\mathbf{1}} \mathbf{C}_{\mathbf{1}}$, complete separation of hydrophobic and hydrophilic regions can be observed in the crystal packing. While the hydrophobic regions are formed by alkyl chains, the hydrophilic part is now more populated and contains the imidazolium head groups, the bromide anions and water. Cohesion inside the crystal structure is ensured by incorporation of water molecules, as neighbouring cations are held together by $\mathrm{CH}^{\cdots} \cdots \mathrm{Br}$, $\mathrm{CH} \cdots \mathrm{O}$ and additional $\mathrm{OH} \cdots \mathrm{Br}$ interactions (Table 3). Interestingly, as with $\mathbf{C}_{\mathbf{1 2}} \mathbf{C}_{\mathbf{1}} \mathbf{C}_{\mathbf{1}}, \mathbf{C}_{\mathbf{1 2}} \mathbf{C}_{\mathbf{1}} \mathbf{C}_{\mathbf{1 2}} \cdot \mathrm{H}_{2} \mathrm{O}$ shows distinct differences between analogous 1,3-didodecyl-1,2,3-triazolium bromide. ${ }^{48}$ Though all carbon chains in both compounds align identically, no interdigitation has been observed in the latter, while the orientation of the triazolium rings allows efficient $\pi-\pi$ interactions between and $\mathrm{CH}-\pi$ interactions within the

Table 3 Layer distances $d[\AA]$ in the crystalline states and the liquid crystalline phases

\begin{tabular}{lll}
\hline Compound & $d_{\mathrm{Cr}}[\AA]$ & $d_{\mathrm{LC}}[\AA]$ \\
\hline $\mathbf{C}_{\mathbf{1 2}} \mathbf{C}_{\mathbf{1}} \mathbf{C}_{\mathbf{0}}$ & 16.7 & $-^{d}$ \\
$\mathbf{C}_{\mathbf{1 2}} \mathbf{C}_{\mathbf{1}} \mathbf{C}_{\mathbf{1}}$ & 22.2 & 27.8 \\
$\mathbf{C}_{\mathbf{1 2}} \mathbf{C}_{\mathbf{1}} \mathbf{C}_{\mathbf{2}}$ & 30.4 & $-^{a}$ \\
$\mathbf{C}_{\mathbf{1 2}} \mathbf{C}_{\mathbf{1}} \mathbf{C}_{\mathbf{3}}$ & 27.9 & 28.5 \\
$\mathbf{C}_{\mathbf{1 2}} \mathbf{C}_{\mathbf{1}} \mathbf{C}_{\mathbf{4}}$ & 26.2 & $-^{b}$ \\
$\mathbf{C}_{\mathbf{1 2}} \mathbf{C}_{\mathbf{1}} \mathbf{C}_{\mathbf{5}}$ & 21.2 & 23.8 \\
$\mathbf{C}_{\mathbf{1 2}} \mathbf{C}_{\mathbf{1}} \mathbf{C}_{\mathbf{6}}$ & $-{ }^{c}$ & 21.9 \\
$\mathbf{C}_{\mathbf{1 2}} \mathbf{C}_{\mathbf{1}} \mathbf{C}_{\mathbf{7}}$ & 24.5 & 22.7 \\
$\mathbf{C}_{\mathbf{1 2}} \mathbf{C}_{\mathbf{1}} \mathbf{C}_{\mathbf{8}}$ & 23.0 & 22.7 \\
$\mathbf{C}_{\mathbf{1 2}} \mathbf{C}_{\mathbf{1}} \mathbf{C}_{\mathbf{9}}$ & 24.0 & 23.0 \\
$\mathbf{C}_{\mathbf{1 2}} \mathbf{C}_{\mathbf{1}} \mathbf{C}_{\mathbf{1 0}}$ & 25.4 & 23.7 \\
$\mathbf{C}_{\mathbf{1 2}} \mathbf{C}_{\mathbf{1}} \mathbf{C}_{\mathbf{1 1}}$ & 19.6 & 24.8 \\
$\mathbf{C}_{\mathbf{1 2}} \mathbf{C}_{\mathbf{1}} \mathbf{C}_{\mathbf{1 2}}$ & 20.4 &
\end{tabular}

${ }^{a}$ Mesophases coexist and could not be measured. ${ }^{b}$ The liquid crystalline phase exists only in a very small temperature range, no layer spacing could be detected. ${ }^{c}$ The solid phase exists only at low temperature and recrystallization did not occur for this sample. ${ }^{d}$ These compounds exhibit no mesophase. $\mathrm{Cr}=$ crystalline state; LC $=$ liquid crystalline state. 
layers that in large extent can be attributed to a less intense hydrogen bond network.

\section{Mesophase investigations with POM and SAXS}

Mesophase formation was observed for all the compounds except for $\mathbf{C}_{\mathbf{1 2}} \mathbf{C}_{\mathbf{1}} \mathbf{C}_{\mathbf{4}}, \mathbf{C}_{\mathbf{1 2}} \mathbf{C}_{\mathbf{1}} \mathbf{C}_{\mathbf{6}}$ and $\mathbf{C}_{\mathbf{1 2}} \mathbf{C}_{\mathbf{1}} \mathbf{C}_{\mathbf{0}}$. The corresponding polarizing optical micrographs for all the liquid crystalline compounds are shown in Fig. S89-S101, ESI.†

Focal conic fan textures, Schlieren textures and oily streak textures can be observed. All of these are textures are characteristic of smectic mesophases. For compounds $\mathbf{C}_{\mathbf{1 2}} \mathbf{C}_{\mathbf{1}} \mathbf{C}_{\mathbf{9}}$ and $\mathbf{C}_{\mathbf{1 2}} \mathbf{C}_{\mathbf{1}} \mathbf{C}_{\mathbf{1 0}}$, a bluish domain texture without the polarising filter could be observed, changing to violet before melting (Fig. S95 and S96†), which is considered to be indicative of bowshaped molecules. The layer spacing distances $d$ of all compounds in the crystalline states and the liquid crystalline phases are summarized in Table 3.

Based on the crystalline structure of $\mathbf{C}_{\mathbf{1 2}} \mathbf{C}_{\mathbf{1}} \mathbf{C}_{\mathbf{1}}$ as evidenced by SXRD, the large layer spacing in the crystalline phase could be explained by a model shown schematically in Fig. 9 (left). The molecules form a herringbone-like bilayer arrangement; the polar head groups line up along a row, and the long-chain tails tilt in alternate directions. Upon heating, the long alkyl chains presumably stretch parallel to the normal of the layer plane, resulting in an increased $d$ spacing in agreement with a smectic A phase (Fig. 10, right). According to the SAXS data, smectic A phases also form for compounds $\mathrm{C}_{12} \mathrm{C}_{1} \mathrm{C}_{3}-\mathrm{C}_{12} \mathrm{C}_{1} \mathrm{C}_{5}$.

For $\mathbf{C}_{\mathbf{1 2}} \mathbf{C}_{\mathbf{1}} \mathbf{C}_{\mathbf{7}}-\mathbf{C}_{\mathbf{1 2}} \mathbf{C}_{\mathbf{1}} \mathbf{C}_{\mathbf{1 0}}$, the layer spacings in the mesophases are shorter than the layer spacings in the crystals. This indicates that the structure undergoes a transition to smectic C phase, where the alkyl chains of cations are tilted with respect to the layer normal. An increase in interdigitation could explain the falling trend for the layer spacing $d$ with rising $n$. A decrease of $5 \AA$ in layer spacing could be observed between $\mathbf{C}_{\mathbf{1 2}} \mathbf{C}_{\mathbf{1}} \mathbf{C}_{\mathbf{4}}$ and $\mathbf{C}_{\mathbf{1 2}} \mathbf{C}_{\mathbf{1}} \mathbf{C}_{5}$. The

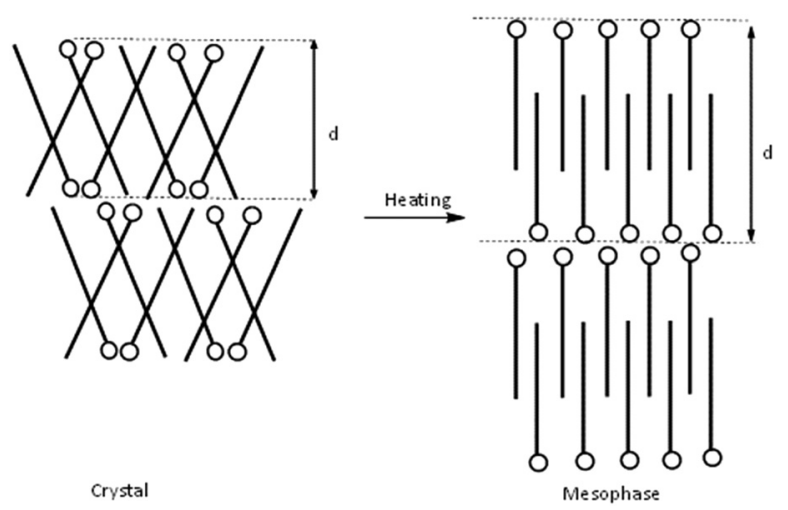

Fig. 10 Illustration of the changes in molecular arrangement of $\mathrm{C}_{12} \mathrm{C}_{1} \mathrm{C}_{1}$ from the crystalline state to the mesophase: herringbone-like structure in the crystalline phase (left) and lamellar smectic liquid crystalline phase (right). rapid change in the $d$ value indicates a principal geometric change in the molecular conformation. This could be a result of decreasing the angle of the varying alkyl chain tilt with respect to the dodecyl chains. We believe a $\mathrm{V}$-shaped molecule could be formed in this way for $\mathbf{C}_{\mathbf{1 2}} \mathbf{C}_{\mathbf{1}} \mathbf{C}_{5}-\mathbf{C}_{\mathbf{1 2}} \mathbf{C}_{\mathbf{1}} \mathbf{C}_{\mathbf{1 0}}$, where the angle between the two alkyl chains at both sides of the 2-methylimidazolium ring remains roughly constant with rising $n$ since the $d$ values in the crystalline state are almost unchanging. The slight increase in the $d$ values could be explained by the insertion of methylene groups. The observation of blue-violet domains in the POM images is also in agreement with our supposition: a presence of a $\mathrm{V}$-shaped structure.

The sudden decrease in layer distances in $\mathbf{C}_{\mathbf{1 2}} \mathbf{C}_{\mathbf{1}} \mathbf{C}_{\mathbf{1 0}}$ and $\mathbf{C}_{12} \mathbf{C}_{\mathbf{1}} \mathbf{C}_{11}$ of approximately $5 \AA$ can be considered to be a molecular conformational change from $\mathrm{V}$-shaped to U-shaped. Single crystal data shows that $\mathbf{C}_{\mathbf{1 2}} \mathbf{C}_{\mathbf{1}} \mathbf{C}_{\mathbf{1 2}}$ arranges itself as interdigitated U-shaped molecules in the solid-state. We could imagine that such U-shaped conformation is already adopted above $n=11$. A crude representation of the three shape types supposed for the 1-dodecyl-2-methyl-3alkylimidazolium cations is shown in Fig. 11.

$\mathbf{C}_{12} \mathbf{C}_{1} \mathbf{C}_{11}$ and $\mathbf{C}_{12} \mathbf{C}_{1} \mathbf{C}_{12}$ show an increased $d$ value in the mesophase (23.7 $\AA\left(\mathbf{C}_{\mathbf{1 2}} \mathbf{C}_{\mathbf{1}} \mathbf{C}_{\mathbf{1 1}}\right)$ and $24.8 \AA\left(\mathbf{C}_{\mathbf{1 2}} \mathbf{C}_{\mathbf{1}} \mathbf{C}_{\mathbf{1 2}}\right)$ compared to the crystal phase $\left(19.6 \AA\left(\mathbf{C}_{\mathbf{1 2}} \mathbf{C}_{\mathbf{1}} \mathbf{C}_{\mathbf{1 1}}\right)\right.$ and $20.4 \AA$ $\left.\left(\mathbf{C}_{\mathbf{1 2}} \mathbf{C}_{\mathbf{1}} \mathbf{C}_{\mathbf{1 2}}\right)\right)$. The U-shaped molecules are able to move with respect to one another in the direction of the interdigitated alkyl chains during heating and cooling processes. A smectic A phase can, therefore, be formed by simply decreasing the interdigitated region.

Generally speaking, these findings correspond to the previously reported result on the non-methylated imidazolium analogues. ${ }^{44}$ The triazolium analogues, on the other hand, present another behaviour as even for longer chain length, the layer spacing in the mesophase appears to be shorter than in its crystalline form. ${ }^{48}$ For the shorter alkyl chains $\left(\mathrm{C}_{1}\right.$ and $\mathrm{C}_{2}$ ), however, all the analogues present the same behaviour; the layer spacing in the liquid crystalline phase is much larger than in the crystal form.

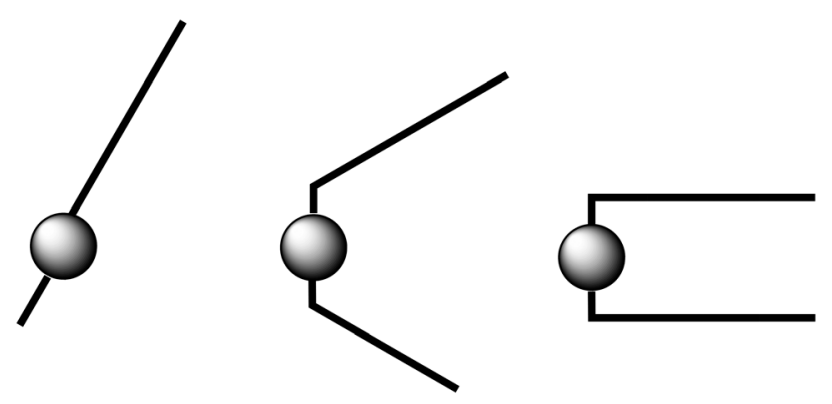

Fig. 11 Illustration of the three shape types observed for $C_{12} C_{1} C_{n}$ cations: (near-linear structures are shown for $n=0-4$, (left); a V-shaped configuration might be formed for $5 \leq n \leq 10$, (middle); a $\mathrm{U}$-shaped molecule might be supposed for $n=11,12$ (right)). 


\section{Conclusions}

In conclusion, we have prepared a series of 1-dodecyl-2methyl-3-alkylimidazolium bromides of which the thermal behaviour has been investigated by DSC, POM and SAXS experiments. The main focus was directed at elucidating their thermal behaviour and structure. Furthermore, crystal structures of $\mathbf{C}_{12} \mathbf{C}_{1} \mathbf{C}_{1}$ and $\mathbf{C}_{12} \mathbf{C}_{1} \mathbf{C}_{12} \cdot \mathrm{H}_{2} \mathrm{O}$ and $\mathbf{C}_{12} \mathbf{C}_{1} \mathbf{C}_{\mathbf{0}}$ could be obtained. All thirteen compounds could be considered ILs since they exhibit a melting point below $100{ }^{\circ} \mathrm{C}$. For $\mathbf{C}_{\mathbf{1 2}} \mathbf{C}_{\mathbf{1}} \mathbf{C}_{\mathbf{4}}$, $\mathbf{C}_{12} \mathbf{C}_{1} \mathbf{C}_{6}$ and $\mathbf{C}_{12} \mathbf{C}_{\mathbf{1}} \mathbf{C}_{\mathbf{0}}$ no thermotropic liquid crystalline behaviour is observed. The absence of mesophase formation for these three compounds was anticipated according to findings for the analogous 1-dodecyl-3-alkylimidazolium bromides. In the previous study, this absence of liquid crystallinity was attributed to the formation of a bilayer structure with an increase in the complexity of interactions between the anion and cation. ${ }^{44}$ One can assume a similar effect for the three aforementioned compounds. Elimination of liquid crystallinity after methylation at the $\mathrm{C} 2$ position has been reported for imidazolium dodecylsulfonate by Mukai et $a l^{45}$ For LC formation, a balance between attractive van der Waals forces and electrostatic repulsion is required.

In comparison with the 1-dodecyl-3-alkylimidazolium salts reported in our previous report, after insertion of the methyl group on the $\mathrm{C} 2$ position, an increase of both the melting points and clearing points of all the compounds can be observed in this series. This increase is consistent with the previous report and originates from the reduced entropy. ${ }^{11,23}$ In addition, $\mathrm{C} 2$ methylation induces a decrease in liquid crystallinity for $n \leq 6$, but above $n \geq 7$ an increase in the mesophase temperature ranges can be observed and with significantly higher clearing points.

The data from SAXS and POM measurements of $\mathbf{C}_{\mathbf{1 2}} \mathbf{C}_{\mathbf{1}} \mathbf{C}_{\boldsymbol{n}}$ compounds suggest three different cation conformations: for $n=0-4$, the molecules show near-linear structures; for $5 \leq n$ $\leq 10$, a V-shaped conformation is postulated; and for $n=11$, 12, a U-shaped molecule might be assumed.

The removal of the most acidic proton at the $\mathrm{C} 2$ position, by either methylation or substitution by nitrogen, provides researchers with a new way to fine-tune the thermal properties of imidazolium derivatives ILs by controlling their decomposition point, extending their liquid crystalline behaviour and tweaking their melting point.

\section{Conflicts of interest}

There are no conflicts to declare.

\section{Acknowledgements}

This work was supported in part by the German Science Foundation DFG through the priority program 1191 "Ionic Liquids" and the DESY (Deutsches Elektronensynchrotron), proposal no. I-20100011, and the Royal Swedish Academy of Science through the Göran Gustafsson prize in Chemistry and
Energimydigheten. We would like to thank Dr. Sergio Funari, for support during the SAXS measurements.

\section{References}

1 A. Getsis and A.-V. Mudring, Acta Crystallogr., Sect. E: Struct. Rep. Online, 2005, 61, 2945-2946.

2 A. Getsis and A.-V. Mudring, Cryst. Res. Technol., 2008, 43, 1187-1196.

3 S. Tang, A. Babai and A.-V. Mudring, Angew. Chem., Int. Ed., 2008, 47, 7631-7634.

4 A. Getsis, B. Balke, C. Felser and A.-V. Mudring, Cryst. Growth Des., 2009, 9, 4429-4437.

5 A. Getsis and A.-V. Mudring, Z. Anorg. Allg. Chem., 2010, 636, 1726-1734.

6 A. Getsis and A.-V. Mudring, Eur. J. Inorg. Chem., 2011, 2011, 3207-3213.

7 M. Yang, B. Mallick and A.-V. Mudring, Cryst. Growth Des., 2013, 13, 3068-3077.

8 X. Wang, F. W. Heinemann, M. Yang, B. U. Melcher, M. Fekete, A.-V. Mudring, P. Wasserscheid and K. Meyer, Chem. Commun., 2009, 7405-7407.

9 P. Wasserscheid and T. Welton, Ionic Liquids in Synthesis, Wiley-VCH, Weinheim, 2007.

10 A.-V. Mudring, Aust. J. Chem., 2010, 63, 544-564.

11 P. A. Hunt, J. Phys. Chem. B, 2007, 111, 4844-4853.

12 A. Mele, G. Romanò, M. Giannone, E. Ragg, G. Fronza, G. Raos and V. Marcon, Angew. Chem., Int. Ed., 2006, 45, 1123-1126.

13 K. Fujii, T. Mitsugi, T. Takamuku, T. Yamaguchi, Y. Umebayashi and S. Ishiguro, Chem. Lett., 2009, 38, 340-341.

14 K. Fumino, A. Wulf and R. Ludwig, Angew. Chem., Int. Ed., 2008, 47, 8731-8734.

15 S. Zahn, G. Bruns, J. Thar and B. Kirchner, Phys. Chem. Chem. Phys., 2008, 10, 6921-6924.

16 G. Wang, M. Valldor, S. Siebeneichler, M. Wilk-Kozubek, V. Smetana and A.-V. Mudring, Inorg. Chem., 2019, 58, 13203-13212.

17 P. Ghosh and A.-V. Mudring, Nanoscale, 2016, 8, 8160-8169.

18 K. M. Lee, C. K. Lee and I. J. B. Lin, Chem. Commun., 1997, 899-900.

19 J. N. A. Canongia Lopes and A. A. H. Pádua, J. Phys. Chem. B, 2006, 110, 3330-3335.

20 A. Triolo, O. Russina, H.-J. Bleif and E. Di Cola, J. Phys. Chem. B, 2007, 111, 4641-4644.

21 L. Crowhurst, P. R. Mawdsley, J. M. Perez-Arlandis, P. A. Salter and T. Welton, Phys. Chem. Chem. Phys., 2003, 5, 2790-2794.

22 H.-C. Chang, J.-C. Jiang, W.-C. Tsai, G.-C. Chen and S. H. Lin, J. Phys. Chem. B, 2006, 110, 3302-3307.

23 T. Endo, T. Kato and K. Nishikawa, J. Phys. Chem. B, 2010, 114, 9201-9208.

24 C. Hardacre, J. D. Holbrey, S. E. J. McMath, D. T. Bowron and A. K. Soper, J. Chem. Phys., 2002, 118, 273-278.

25 E. J. Maginn, J. Phys.: Condens. Matter, 2009, 21, 373101. 
26 Y. Yoshida, O. Baba, C. Larriba and G. Saito, J. Phys. Chem. $B, 2007,111,12204-12210$.

27 J. Zhu, L. Bai, B. Chen and W. Fei, Chem. Eng. J., 2009, 147, 58-62.

28 P. Bonhôte, A.-P. Dias, N. Papageorgiou, K. Kalyanasundaram and M. Grätzel, Inorg. Chem., 1996, 35, 1168-1178.

29 F. F. C. Bazito, Y. Kawano and R. M. Torresi, Electrochim. Acta, 2007, 52, 6427-6437.

30 S. T. Handy and M. Okello, J. Org. Chem., 2005, 70, 1915-1918.

31 C. P. Fredlake, J. M. Crosthwaite, D. G. Hert, S. N. V. K. Aki and J. F. Brennecke, J. Chem. Eng. Data, 2004, 49, 954-964.

32 P. W. Lohse, R. Bürsing, T. Lenzer and K. Oum, J. Phys. Chem. B, 2008, 112, 3048-3057.

33 T. Itoh, Y. Nishimura, N. Ouchi and S. Hayase, J. Mol. Catal. B: Enzym., 2003, 26, 41-45.

34 A. E. Bradley, C. Hardacre, J. D. Holbrey, S. Johnston, S. E. J. McMath and M. Nieuwenhuyzen, Chem. Mater., 2002, 14, 629-635.

35 K. Binnemans, Chem. Rev., 2005, 105, 4148-4204.

36 L. Douce, J.-M. Suisse, D. Guillon and A. Taubert, Liq. Cryst., 2011, 38, 1653-1661.

37 M. Yang, P. S. Campbell, C. C. Santini and A.-V. Mudring, Nanoscale, 2014, 6, 3367-3375.

38 M. Yang, K. Stappert and A.-V. Mudring, J. Mater. Chem. C, 2014, 2, 458-473.

39 K. V. Axenov and S. Laschat, Materials, 2011, 4, 206-259.
40 A. Taubert, C. Palivan, O. Casse, F. Gozzo and B. Schmitt, J. Phys. Chem. C, 2007, 111, 4077-4082.

41 A. Taubert, Angew. Chem., Int. Ed., 2004, 43, 5380-5382.

42 A. Taubert, F. Stange, Z. Li, M. Junginger, C. Günter, M. Neumann and A. Friedrich, ACS Appl. Mater. Interfaces, 2012, 4, 791-795.

43 P. S. Campbell, M. Yang, D. Pitz, J. Cybinska and A.-V. Mudring, Chem. - Eur. J., 2014, 20, 4704-4712.

44 M. Yang, B. Mallick and A.-V. Mudring, Cryst. Growth Des., 2014, 14, 1561-1571.

45 T. Mukai, M. Yoshio, T. Kato and H. Ohno, Chem. Lett., 2004, 33, 1630-1631.

46 P. H. J. Kouwer and T. M. Swager, J. Am. Chem. Soc., 2007, 129, 14042-14052.

47 C. Li, J. He, J. Liu, L. Qian, Z. Yu, Q. Zhang and C. He, J. Colloid Interface Sci., 2010, 349, 224-229.

48 K. Stappert and A.-V. Mudring, RSC Adv., 2015, 5, 16886-16896.

49 S. Sanghi, E. Willett, C. Versek, M. Tuominen and E. Bryan Coughlin, RSC Adv., 2012, 2, 848-853.

50 P. Wasserscheid and T. Welton, Ionic Liquids in Synthesis, John Wiley \& Sons, 2008.

51 A. Hunt, J. Phys.: Condens. Matter, 1992, 4, L429-L431.

52 V. R. Thalladi, M. Nüsse and R. Boese, J. Am. Chem. Soc., 2000, 122, 9227-9236.

53 J. D. Holbrey and K. R. Seddon, J. Chem. Soc., Dalton Trans., 1999, 2133-2140.

54 X. Wang, C. S. Vogel, F. W. Heinemann, P. Wasserscheid and K. Meyer, Cryst. Growth Des., 2011, 11, 1974-1988. 